\title{
Effective Care Management
}

\author{
David Challis
}

\section{Universities of Manchester and Kent}

1. Origins and Rationale

There are broad similarities in the changing pattern of services for older people in numerous countries. All involve shifting or maintaining the balance of care in the face of rising demand. These changes may be characterised in simple form as firstly, a move away from institution-based provision of care; secondly, the extension of home-based care, and thirdly, for individuals with more intense needs, the development of mechanisms of care coordination, usually through the medium of case or care management. ${ }^{1}$

There is a particular role for care management in the process of shifting the balance of care. Its purpose in policy is frequently to provide a context to improve targeting of individuals into appropriate care options so that institutional care is reserved for the most disabled and, by extending the capacity of home-based care, reducing the rate of growth of institutional care for an ageing population may be reduced. Thus it functions to extend the capacity and extent of home care so that the boundary between maximum home care and the level of support in institutional care is narrowed. A second and less specific use of care management in fragmented care systems is to link a wider range of people in need of support with services which by the nature of the care system come from a variety of providers, and possibly through multiple funding sources. There can be seen here a simple distinction emerging between intensive care management-a highly focused and targeted activity and coordinative care management-received by a larger population of service users to achieve effective service allocation.

Hence there emerges the need to relate care management, and notions of what constitutes effectiveness in this area of activity to its precise purposes and target population. In general it is reasonable to postulate a simple axiom-the more fragmented the care system and its funding mechanisms, the lower the threshold of intervention where care management is seen to be required.

A discussion of effective care management in long term care needs explicit focus upon the key question: Who receives what kind of care management to achieve what goals with what resources in which setting?

Herein lies a source for some of the difficulties in care management implementation in long term care. Does it constitute coordination of services for a wide range of needy individuals or a specialised approach for a smaller number? An attempt at definition so as to differentiate approaches may assist.

\section{Definition}

A variety of definitions of care management may be found in the literature which permit variability of interpretation. For example the UK Department of Health defines care management broadly as the process of tailoring services to needs, and then specifies a range of care tasks such as assessment and review as core activities. ${ }^{2}$ It may be more helpful to offer a multi-variate definition of care management for the purpose of providing long term care as a means of resolving some of the difficulty.

It is helpful to identify six criteria which together enable a more precise definition to be formulated. These are the performance of a set of core tasks; the function of coordination; explicit goals for care management; a focus upon long term care needs; particular features which differentiate care management from the activities of other community based professionals; and the dual function of care management at client level and system level. ${ }^{3}$ These are shown in Table 1 and are discussed below. They attempt to answer the questions of:

How care management is done?

What is undertaken in care management? 
Why is it care management employed in the care system?

For whom is care management provided?

What makes care management different from other community based work?

What impact does care management have on the service system?

\section{Table 1: Defining Care Management}

\begin{tabular}{|l|l|}
\hline $\begin{array}{c}\text { Key Attributes of Care } \\
\text { Management }\end{array}$ & \multicolumn{1}{c|}{ Distinctive features } \\
\hline - Core tasks & $\begin{array}{l}\text { - Case-finding and screening; assessment; care planning; monitoring and } \\
\text { review; case closure }\end{array}$ \\
\hline - Functions & - Coordination and linkage of care services; tailoring resources to needs \\
\hline - Goals & $\begin{array}{l}\text { - Providing integrated care with continuity; Increasing the feasibility of } \\
\text { care at home; promote client well-being; making better use of resources }\end{array}$ \\
\hline - Target Population & $\begin{array}{l}\text { Those with long term care needs; multiple service recipients; those at } \\
\text { risk of losing community tenure }\end{array}$ \\
\hline - Differentiating features & $\begin{array}{l}\text { Intensity of involvement; breadth of services spanned; duration of } \\
\text { involvement }\end{array}$ \\
\hline - Multi-level response & $\begin{array}{l}\text { Linking practice level activities with broader resource and } \\
\text { agency level activities }\end{array}$ \\
\hline
\end{tabular}

Most definitions of care management tend to begin with the performance of a series of core tasks in long-term care. Although the precise number of tasks and the label given to them may vary they are broadly similar. The core tasks include case finding and screening, assessment, care planning, implementing and monitoring the care plan. The core tasks are designed to achieve a greater degree of integration of care and hence the second element in definition is that of achieving coordination. This is based upon an assumption that care management provides continuity of care and in most of the more intensive definitions of the role this involves continuity of support by a dedicated individual or team who will organise, coordinate and sustain a network of support.

The integrated care which the performance of the core tasks is designed to achieve is seen as linked to achieving specific goals. These goals have been most commonly concerned with the shift in the margin between institutional and home-based care, cost containment, community tenure and individual independence, but have also been related to the enhancement of the capacity of social networks and the improvement of clients' utilisation of support systems.

The specification of a clear target population constitutes the fourth aspect of a definition of care management, which is most usually operationalised as a concern with meeting the needs of people with long-term care problems or multiple needs. This perception of its role as a mechanism for providing long-term community-based care and therefore relevant to a specific target population, is an element which helps to differentiate care management from the activities of other community-based workers. This lack of clarity of differentiation is at times debated in the literature and the role is often seen as closely linked to that of social workers and nurses who in practice are the occupational groups as commonly acting as care managers. Three elements which do appear to differentiate the activities of long-term care case management from activities such as key working have been identified as 'Intensity of Involvement'-reflected in relatively small caseloads; 'Breadth of Services Spanned'covering more than one service, team or agency; and 'Length or Duration of Involvement' - a long-term commitment.

The distinction has also been made between single agency coordination and comprehensive case management, the latter involving an inclusive examination across a person's needs and resources, linking them to a full range of appropriate services, using all available funding sources and monitoring the care provided over an extended period of time. The final factor which can be seen to differentiate care management approaches from others is the focus of operation both at the client-level and the system-level. Care management is seen as relevant to providing care for the individual but also for shifting the pattern of services in ways which are more client-centred and thereby effective. In purchasing terms this is based upon the assumption that the aggregate of a myriad of individual care provision decisions may 
exert pressure for change upon patterns of provision themselves. Thus the degree of horizontal integration which may be achieved by care management at the practice-level requires a corresponding degree of vertical integration into the system in order to be effective.

Hence care management is too broad a concept in the absence of precise definition. Using this definition most research findings relate to a narrow conception of care management in long term care, with the more precisely defined programmes tending to have the more evident outcomes.

3. Effectiveness and features associated with positive outcomes

Most evaluation research of care management programmes has been concerned with the intensive support of high risk or high need groups in both mental health and ageing. These studies have focused upon populations with high probability of admission or readmission to hospital or nursing home settings. Despite this diversity and the difficulty of producing reliable and robust definitions of attributes such as severe mental illness or risk of nursing home placement, there is a considerable degree of consistency in the findings. From these studies several factors may be identified which appear to be associated with effective outcomes in long-term care management. These are shown in Table 2. As can be seen, these include integrated funding for the programme, clarity and precision of target population, clear service objectives, continuity of involvement, and logical linkages between the model of care management, its objectives and the incentives which the structures present to the practitioners implementing the programme. At the practice level this may refer to such factors as appropriate caseload sizes and the means to be able to respond creatively to identified needs, through such mechanisms as devolved budgets.

\section{Table 2: Some Factors Associated with Effective Outcomes in Care Management}

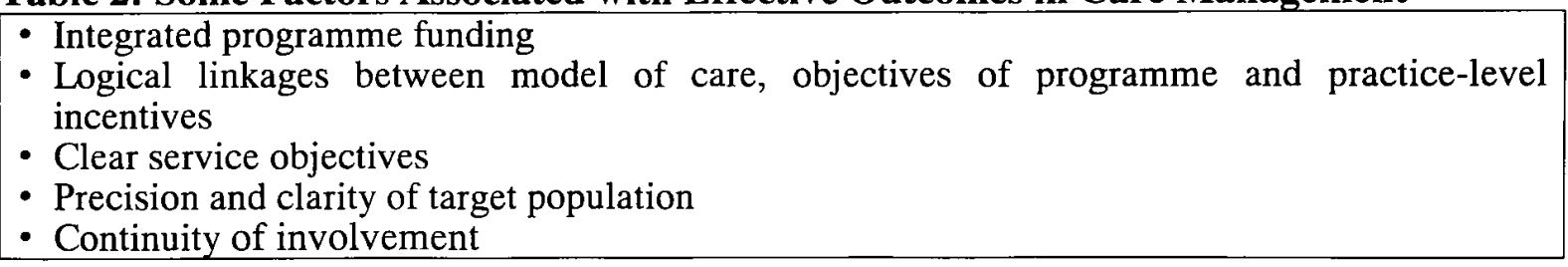

Integrated funding can avoid some artificial boundaries and perverse incentives arising from organisational pressures to remain within narrow budgetary confines. Clarity of target population, combined with systems of screening and assessment, can ensure that care management with its inevitably higher overhead costs is provided to those for whom it is most appropriate. Clear service objectives provide a focus for managing and monitoring care management programmes whether in terms of needs of recipients, service processes such as costs, or outcomes such as hospitalisation, community tenure or quality of life. Continuity of involvement offers the basis of practitioners remaining responsible for assessing, monitoring and reviewing cases and gaining the benefits of feedback from effective and ineffective strategies, whether at the individual case level or more generally. Logical linkages between programme goals, environment and practice incentives reflects the necessity for congruence between practice environment and overall objectives. For example, such components as flexible patterns of response, perhaps by means of devolved budgets, need to be available to care managers if a programme goal is for individually tailored services. In the absence of such flexibility, or where there is marked difficulty in providing other than standard responses, the incentive for practitioners will be to respond in a very standard fashion rather than to individualise care.

\section{Key aspects to be addressed in long term care systems}

There are some key aspects of care management which need to be addressed if it is to operate as part of an effective long term care system.

The need for a differentiated response: The degree of apparent confusion between care management as simply a description of the organisational process involved in assessing and providing services to people in need and care management as an activity undertaken by a designated worker for a specific client group has been observed in the UK. The need for a further distinction between 'coordinative care management' and 'intensive care management' 
was made earlier in this paper. Discussion of the role of care management in long term care cannot be conducted until specific types of care management are related to specific types of need groups. For much long term care provision it is care management of the intensive kind which is likely to be required, characterised by a more professional orientation among staff, smaller caseloads and resource rich responses to need.

A focused and effectively targeted client group: Differentiated response to need implies targeting of response and the presence of adequate screening mechanisms to implement this. Effective targeting appears to have been a crucial factor associated with positive outcomes in care management. In many of the programmes, particularly for older people, targeting has been associated with the propensity to enter institutional modes of care. This has reflected the desire to shift the balance of care from institutional modes towards community-based care. However, whilst current policies may wish to shift the balance of provision of care, in the longer term some desired balance may well be achieved. In a context of maintenance of a balance of care, targeting may have to be sharpened further, so that the investment of expensive services to coordinate care, such as intensive care management, are focused upon those who would make most gain from the provision of such service. This is a problem in social care analogous to the concept of 'health gain' in health care.

Balance of activities: assessment, monitoring and review: Although care management in the UK has been associated with assessment as one of the cornerstones of the implementation of community care policy, the precise contribution of health care and of particularly secondary health care services such as geriatric medicine and old age psychiatry to this process are not clearly specified and are subject to local arrangements. Care management systems devised in agency isolation and lacking access to appropriate expertise for assessment are unlikely to be fully effective, particularly when dealing with individuals with complex problems. Where screening is lacking care management systems may become unbalanced with excess staff time devoted to the assessment of new cases and insufficient time to review of existing cases. A consequence is likely to be growing a mismatch of resources to needs.

Early monitoring of the development of care management in the UK suggested that a large numbers of people had entered the care management process and the assessment procedures were making heavy demands upon scarce practitioner time, it was being found increasingly difficult to undertake review processes. This was particularly so with the build up of reviews of elderly people placed in nursing and residential care homes in the non-statutory sector. There could be a real risk in programme distortion if the growth in demand for reviews in institutional settings was such that staff time was diverted from support of individuals in the community.

Programme consistency: Linking care management system and practice: The critical importance of care management systems possessing a degree of organisational integration more than just at the practice-level appears clear. This is evident in some mental health programmes. Coherent links between funding, contracting and individual case decisions can enhance this. In this way offer a degree of vertical integration of care for very vulnerable individuals may be achieved and this may indicate future roles for geriatric and old age psychiatric services in relation to the development of care management.

Related to the linking of system and practice, it would appear that effectiveness requires there to be a logical coherence between expected outcomes, staffing, settings, target groups, service models, and the day to day pressures and incentives upon practitioners. Lacking this internal consistency an apparently rational model of care management may well fail to achieve its goals.

\section{Conclusion}

An appropriate starting point for debate about the effectiveness of care management in long term care systems must be in a context where target populations are explicit, goals of care management clear, programmes logically integrated, and flows of demand and activity adequately estimated.

References:

1. Challis D, Davies B, Traske K: Community care: promise, imperative and ambition-an 
international agenda. In: Challis D, Davies B, Traske K, eds, New Agendas and Challenges from the UK and Overseas, Aldershot, Ashgate, 1994

2. Social Services Inspectorate/Social Work Services Group (SSI/SWSG): Care Management and Assessment: Managers' Guide, London, HMSO, 1991

3. Challis D, Darton R, Johnson L, Stone M, Traske K: Care Management and Health Care of Older People, Aldershot, Ashgate, 1995

Further readings:

Challis D: Care management. In: Malin N, ed, Implementing Community Care, Buckingham, Open University Press, 1994 


\title{
Japan's Long-term Care Insurance System: The Likely Impact on Service Suppliers and their Staffs
}

\author{
Mikiko Eto
}

\section{Hosei University}

The Long-term Care Insurance (LTCI) system that is scheduled to start in April 2000 will change the existing Japanese welfare system in two respects. First, the basic principle of eligibility will be altered. Under the 1963 Welfare for the Elderly Law, services have been based on a means-tested poverty program model, mainly aimed at older people without families. In contrast, the new system is based on the principle of universality, under which all insured elderly people are qualified to receive services, not based on their economic or family conditions, but just on their needs arising from disability.

Second, the institutional arrangements for service supply will be revised. Under the present system, either municipal authorities or nonprofit "social welfare corporations" (shakai fukushi houjin) provide welfare services for the elderly, such as nursing homes, day care centers and home help services. Under the new system, medical facilities, private enterprises, and other kinds of non-profit organizations will also be able to provide welfare services. This reform is intended to expand the number of suppliers and thus the supply of services, and to give recipients more freedom of choice and suppliers more competition. Naturally, many existing suppliers are quite worried about the change.

I would like to focus my attention on the latter aspect of the expected changes; namely, what dynamics will occur among the suppliers, how each supplier will cope with the new situation, and who will grasp and who is likely to miss these new opportunities. I will also briefly discuss the changing relationship between medical and welfare specialists under the new system.

Service Provision Under the Present System?

The current system is managed by the municipal authorities. They control the balance between demand and supply, selecting from among many applicants using criteria such as how well they can get along in daily life, personal and family income, and family composition. An applicant who earns a low income and lives alone is likelier to get benefits than someone else with the same disability. The beneficiary receives services from the supplier designated by the authorities; the recipient is unable to choose his or her favorite supplier. The suppliers are managed either directly by the municipality or-most often-by a social welfare corporation, operating with a subsidy from the local authorities.

The welfare corporations are public sector entities prescribed by the Social Welfare Programs Act of 1951. They are prohibited from offering any services other than those assigned by the authorities. While many of them are philanthropic organizations established by religious or charitable groups, recently corporations established by the municipal authorities themselves have increased, due to financial difficulties that arise from directly providing services.

\section{How Will Service Provisions Change?}

Under the new LTCI system, the municipal authorities must establish a committee to assess eligability and level of need. This committee must be in the third sector, independent of the municipal authorities, and be made up of professionals and experts related to health and welfare services, appointed by the mayor. The committee first assesses whether or not an applicant is qualified or not, and if so, at which of six dependency levels. This decision is based on statistical analysis of a questionaire administered by an interviewer dispatched by the municipal authorities, the interviewer's brief qualitative report, and the opinion of the
applicant's home doctor.

At the request of a beneficiary, a care manager may write up a care plan for the amount of services allowed at that level of dependency. The beneficiary can select the supplier, and if 
he or she needs several services, each can come from a different supplier. Moreover, a beneficiary can purchase services at his or her own expense to supplement the services provided by the public insurance. It is said that this freedom of choice is one of the important merits of the LTCI system. Since it means that the beneficiary is responsible for his or her own choices, it is important that an adequate system for advocacy and consulting be established for service recipients.

The LTCI market is open to all suppliers that meet a fixed standard, which varies according to the kinds of services; for example, the standard for approving the provision of nursing home services is stricter than those of various in-home services. The regulation of suppliers will be much looser than with the existing system. Now, private enterprises that have been barred from the existing system because they are profit-making, and also non-profit organizations that have not qualified under the rules for welfare corporations, will now be able to enter the new market. Medical facilities too will be able to participate in the LTCI system. Although competition among various suppliers brings the merit of cost-effectiveness, it is feared that excessive competition work to the disadvantage of conscientious suppliers and possibly force them out of the market. The question has been raised of whether or not market mechanisms can coexist with an ideal of welfare.

\section{How Will Suppliers React?}

What will be the reactions among old and new suppliers to the situation caused by the creation of LTCI? By seeing the actions that they have already taken, we can try to predict what they will do under the new system.

\section{Municipalities}

It is the municipalities that actually are in charge of the insurance. They are faced with three problems: (1) how to collect the premiums, (2) how to ensure a sufficient supply of services and (3) how to manage the system. With regard to the first problem, since lowincome elderly and self-employed people may not pay their premiums, the municipalities where the rate of aging is high are particularly afraid of being unable to obtain the funds they need. Also, many municipalities worry that they will not be able to secure a sufficient supply of services to meet the needs of the insured.

On the other hand, if the market mechanism works well, the more the needs increase, the more the supply of services should grow. In the meantime, management problems are likely to be the most difficult for the municipalities: how can they control the increase of expenditures, what advocacy system is needed to protect the rights of beneficiaries, and how can they control "dishonest" suppliers? There are two possibilities for the municipalities: they can elect to focus on only the revenue and expenditure of insurance funds, or they can try to extend their management to the total system.

\section{Social Welfare Corporations}

Under the current system, municipalities have protected the social welfare corporations. On the one hand, municipal regulations have restricted the activities of the social welfare corporations, but on the other hand, their subsidies have provided stability. The existing system has provided so much protection to the social welfare corporations that the prospect of deregulation throws them into confusion. While some corporations are trying to adapt themselves to the new environment in a positive way, so far most are not really responding. If they cannot reform themselves and find new direction, they may be forced to withdraw from the LTCI market.

\section{Medical Facilities}

Hospitals and clinics would seem to be offered some new business chances just when the government is moving sharply toward restraining medical expenditure. As mentioned above, doctors provide an opinion in the assessment process, but they are at the same time service suppliers. One point is that long-term care hospitals with elderly patients will in effect become nursing homes paid by LTCI benefits. Moreover, even beneficiaries living at home will be needing some services from medical facilities. If these facilities provide not only medical services but also social services, they would be able to capture large numbers of clients. 
Non-profit Organizations (NPOs)

A few NPOs have begun to provide community-based social services since the 1980 s. Their activities vary from nursing homes to meal delivery services. For example, a large NPOs in Kanagawa Prefecture has established a social welfare corporation that manages a nursing home and a day care center, with a subsidy from municipalities. Such an example is, however, a rare case. Most NPOs are small groups and are always worried about shortages of funds, because they have not been approved as public sector corporations under the present system. They may be able to find good opportunities in deregulation, but it is uncertain how many of them will really be able to succeed in enlarging their activities.

\section{Private Enterprises}

Private enterprises are powerful rivals for the social welfare corporations and NPOs. They seem likely to try to become suppliers of multiple services. Just as customs prefer a supermarket to a retail store because of the convenience of one-stop shopping, a beneficiary may wish to choose a commercial all-inclusive supplier.

Who Will Take the Initiative?; Cooperation Rather than Confrontation

This competition may become confrontational. Under the existing welfare system for the elderly, social workers and care workers, namely, welfare experts, have played the central role. Under the new system, medical doctors may insist on taking over the leadership in interactions among LTCI providers. While the welfare experts would like to remain independent of doctors' control, they are also very cautious about the prospect of private enterprises becoming involved, because they doubt that companies will have the true "welfare spirit."

It seems clear that to implement the LTCI system successfully, cooperation between medical and welfare experts is essential. Providers should not worry so much about who is going to take the lead, and should be concerned with how to cooperate among themselves. 


\title{
Models of Long-term Care That Work
}

\author{
Rosalie A. Kane
}

University of Minnesota

In the United States, as is probably true elsewhere, long-term care often seems to fail to "work." By that, I mean that long-term care long-term care seldom meets the inter-related cost, access, and quality criteria by which health and human services programs tend to be judged. Access and cost (that is, price) are particularly inter-twined. A relatively low price for services is important regardless of whether payment is made by the consumer, by governments in a tax-supported program, by governments for low-income people, or by private insurers. If prices are low, access is improved because more services can be provided and more people helped per dollar expended.

Quality is the most important and the most ambiguous of the three criteria. For a program to achieve quality, it must meet its goals with an acceptable, or even better, an excellent standard of performance. I define long-term care this way: health and social services given over a sustained period to people with functional difficulties. From the perspective of those receiving the care, the goal is to enable them to live their lives as meaningfully and productively as possible given the disabilities that created the need for long-term care in the first place. The help needed corresponds literally to the functional impairments-if the consumer needs help to get in and out of bed, to use the toilet, to bathe, to prepare meals, to take medicines, to purchase food and other necessities, then the corresponding services are transferring assistance, toileting assistance, bathing, cooking, administration of medicines, and shopping. If the long-term care consumer has severe memory and judgement problems because of Alzheimer's disease or some other kind of dementia, the services needed may include a particularly labor-intensive supervision for safety.

Ordinarily such services are provided by family members for each other, but if no capable family members are available (often the case, given an aging society and technologically complex service needs), then long-term care must be arranged to supplement or replace the family efforts. Studies in the United States suggest that consumers seek the following in long-term care providers: reliability and trustworthiness; technical competence; compassion and kindness; a personality compatible with their own in those who provide regular personal care. If they need to move to a congregate residential setting, they seek a place that is homelike, where they will continue to exercise control over their lives, and which will not require them to move yet again if they get sicker. More basically, in making decisions about their long-term care, consumers are concerned about their dignity, comfort, continuity with the past, ability to sustain meaningful personal relationships with family members and other, and ability to contribute socially. If the long-term care consumer has dementia, family members seeking care on their behalves, seek to maximize their relative's physical well-being, comfort, and safety, and decent, and seek dignified, compassionate care.

\section{How Long-Term Care Programs Fail}

The ways in which long-term care programs fail to work in the United States include the following individual-level problems:

Consumers and their families cannot find help. If they do find help, they cannot afford it. If they find a public program to help them, the amounts of help are insufficient. If they need housekeeping help, they can only get nursing help. If they need nursing help, they can only get housekeeping help. Personal care at occasional intervals throughout the day and night is particularly hard to arrange.

The need for long-term care arises after a medical crisis. The consumer is in the hospital, family members are anxious, but advice is unavailable.

Consumers are unnecessarily restricted. They are unable to leave their homes because the help they can acquire is limited to services in their own homes. They may not even be able to control what their helpers do and how they behave in their own homes. If they need extensive care and have low incomes, they may be forced to relocate to nursing homes to get 
the services they need or to get financial coverage for those services.

The nursing home, which in the United States provides most of the publicly subsidized long-term care, is unattractive to consumers because of the disruption of familiar lifestyles and relationships, the loss of dignity and privacy associated with life in typical nursing homes, feelings of being abandoned and unprotected, and concern about quality of care.

Systems also fail to work at the societal level. The problems include:

The costs per case and overall are higher than public and private payers can afford.

A mechanism is lacking to quickly identify those who need services and to equitably allocate services. There seems to be an unfair and haphazard aspect to allocation.

There are concerns about the quality of the front-line workers who actually provide services. This has led to mandated training and layers of professional supervision, which has increased the cost but not alleviated the concerns.

Fragmentation between health-oriented and socially-oriented approaches has led to confusion, lack of service, or over-priced services. Some routine services (for example, administration of oral or other medications, managing catheters or ostomies) are interpreted to require close supervision of a nurse, making costs prohibitive at home. On the other hand, when people in a social program need advice of health professionals, it may not be easily acquired. Primary medical care for those getting long-term care is of variable, often poor quality.

Personal care, the service most needed, is in shortest supply.

All regulation and quality assurance seems directed at the over-riding goal of consumer safety and minimizing consumer risks. Providers of service have become liability conscious above all. No mechanism has been developed to hold providers of care reasonably accountable without heavily restricting the way of life of the consumer.

The most money is expended on the kinds of services-nursing homes-that consumers least value.

Long-term care consumers are reluctant to accept services, and typically want fewer inhome services than professionals think are needed for their safety. Although this helps balance budgets, it means that either the person did not need service at all (a case of poor assessment) or, more likely, that the services offered are not perceived as desirable, helpful, or trustworthy.

Systems that Work

In some parts of the United States, long-term care systems appear to work better than average. Public expenditures are better balanced between nursing homes and other in-home and out-of-home arrangements. Consumers and their families have better access to information upon which to make choices. Consumers seem to have more control over planning their care. I conclude with a list of what seem to be the features that most characterize well-working systems. This is obviously a summary. The entire list of features "that work" does not apply to any one program.

The long-term care program is driven by clearly articulated values. These may include dignity, choice, "normal" lifestyles, and independence for the consumer; respect for consumer preference; respect for the family structure, and so on.

At a local level, a single, well-publicized point of access is available for consumers to learn about services that are available and their own eligibility, and to receive help with arranging the services. This implies a uniform assessment and case management process at the local level. This is a conceptual and organizational single access point, not a geographic place. For example, the case management system is available to people who are in the hospital.

A repertoire of services is available in the community, but these services are not arrayed on a "continuum" where professionals can decide what service is "appropriate" on the basis of disability levels. Consumers and their families make choices about the services that work best for them. Flexible, innovative, and unorthodox arrangements can be made.

Personal care is plentifully available. Consumers can choose whether to purchase that care from individually-employed workers whom they largely train and direct (called the Independent Provider [IP] Model, in the Untied States) or from a home care agency. Whether an agency or an IP gives the service, a backup capability is available if the worker does not arrive. 
Under some circumstances, family members of the consumer may be selected as IPs, particularly if such family members withdraw from the labor force to give care.

Safety is not the predominant value in the system, and there is no effort to attribute each death, fall, or worsened health status to somebody's negligence.

Out-of-home possibilities are available for consumers who cannot live in their own homes and efficiently receive the full amount of care needed. These resemble private dwelling places-family homes and apartments-and the price of the housing is separated from the price of the services for reimbursement purposes. Therefore, consumers may pay for the costs of their housing and from their pensions (public and/or private), whereas the long-term care services are viewed separately.

Some analysts believe that if consumers were merely to receive sufficient additional income to purchase long-term care services, the market would bring systems that work. Though an adequate income is part of the solution, it is insufficient. Many long-term care consumers are vulnerable, unable to make decisions because of cognitive impairment, or unable to execute decisions because of physical problems. Without some over-riding planning at the community level and case management available at the individual level, long-term care systems are unlikely to work. If the system works well, long-term care consumers will be seen as and perceive themselves as simply living their lives rather than spending their fulltime as patients or clients of some long-term care program. 